\title{
A new species of Pelidnota MacLeay (Coleoptera, Scarabaeidae, Rutelinae, Rutelini) from Southeast Brazil
}

\author{
André Ferreira ${ }^{1,4}$; Fernando Vaz-de-Mello2,5 \& Freddy Bravo $0^{3,6}$ \\ ${ }^{1}$ Universidade Federal da Bahia (UFBA), Instituto de Biologia (IBI0), Programa de Pós-Graduação em Biodiversidade e Evolução. \\ Salvador, BA, Brasil. \\ 2 Universidade Federal de Mato Grosso (UFMT), Instituto de Biociências (IB), Departamento de Biologia e Zoologia. \\ Cuiabá, MT, Brasil. \\ ${ }^{3}$ Universidade Estadual de Feira de Santana (UEFS), Departamento de Ciências Biológicas (DCBIO), Laboratório de Sistemática de Insetos (LASIS). \\ Feira de Santana, BA, Brasil. \\ ${ }^{4}$ ORCID: http://orcid.org/0000-0001-7003-0772. E-mail: sferreira.and@gmail.com \\ ${ }^{5}$ ORCID: http://orcid.org/0000-0001-9697-320X. E-mail: vazdemello@gmail.com \\ ${ }^{6}$ ORCID: http://orcid.org/0000-0003-0959-0767.E-mail: fbravo@uefs.br
}

\begin{abstract}
Pelidnota MacLeay, 1819 is one of the most diverse genus in Rutelina (Rutelini) and, even after broad and recent revisions, fieldwork has revealed a diversity of species yet to be known to science. Here, we describe Pelidnota silveiranetoi sp. nov. with illustrations and a map for the type locality, as well as its inclusion in a previously published identification key for the Pelidnota species. The new species is diagnosable by its color pattern (body with metallic green reflections, except on the elytra, which lack black spots), mouthpart features (galea bearing three teeth and the anterior part of the labium with an excavated surface, straight proximal margin, and the posterior part with a rounded lateral margin), and parameres (concave distal margin gradually acute and slightly divergent at the apex; straight lateral margin that is slightly sinuous at the middle; slightly corrugated proximal margin).
\end{abstract}

Keywords. Neotropical region; Pelidnotine scarabs; South America; Taxonomy.

\section{INTRODUCTION}

Pelidnota MacLeay, 1819 is one of the most diverse genus in Rutelina (Coleoptera, Scarabaeidae, Rutelinae, Rutelini) (Bouchard et al., 2011), with 195 species and subspecies in the Americas (Moore et al., 2017). In Brazil, 59 species and 31 subspecies are known (Ferreira et al., 2017; Moore et al., 2017). However, according to Grossi \& Vazde-Mello (2020), there are records of 68 species and 25 subspecies of Pelidnota in Brazil. In the state of São Paulo, nine species and seven subspecies are known (Moore et al., 2017). The genus was revised by Soula (2009) and recently by Moore et al. (2017); however, in the same year, Ferreira et al. (2017) described three new species not included in the genus revision.

Here, we describe a new species of Pelidnota according to the set of characters of the genus proposed by Moore et al. (2017). The type locality is plotted on a map, and the species is included in an identification key by Soula (2009) and modified by Ferreira et al. (2017).

\section{MATERIAL AND METHODS}

Three male specimens (ESALQ/USP) were studied. Morphological analyses and comparisons were conducted using a Leica stereomicroscope model S8AP0. All photographs were taken using a Leica stereomicroscope model m205C (7.8X-160.0X) with the MC190 HD image capture system. The terminology used follows that by Beutel \& Lawrence (2005) supplemented by Lawrence et al. (2010) for overall morphology. The body measurements, puncture density, puncture size, and setae density are according to Jameson \& Ratcliffe (2011).

The type material labels were transcribed verbatim between quotation marks ("..."). The single slash (/) is used for a new line on the same label. Label color or other additional information is given in brackets ([...]).

Geographical coordinates were obtained from Google Maps (www.google.com.br/maps). The geographical record was plotted on the map using QGIS version 2.10.1. The final image editing of the geographical record map and the image 
editions were carried out using GIMP version 2.10.22 (https://www.gimp.org/downloads). The parameres line was drawn using INKSCAPE version 1.0.2 (https://inkscape.org/release/inkscape-1.0.2).

The entomological collections cited in this paper are the following:Setor de Entomologia da Coleção Zoológica da Universidade Federal de Mato Grosso, Cuiabá, Mato Grosso, Brazil (CEMT); Coleção Entomológica da Universidade Federal Rural de Pernambuco, Recife, Pernambuco, Brazil (CERPE); and Museu de Entomologia, Departamento de Entomologia, Fitopatologia e Zoologia Agrícola - ESALQ/Universidade de São Paulo, Piracicaba, São Paulo, Brazil (ESALQ/USP).

\section{RESULTS}

\section{Family Scarabaeidae Latreille, 1802 \\ Subfamily Rutelinae MacLeay, 1819 \\ Tribe Rutelini MacLeay, 1819 \\ Subtribe Pelidnotina Burmeister, 1844 \\ Genus Pelidnota MacLeay, 1819 \\ Pelidnota silveiranetoi sp. nov.}

(Figs. 1-5)

Type material: HOLOTYPE (o' CEMT): First label [white, typeset]: "BRAZIL: São Paulo, / Iracemápolis, / 11.ix.2011". Second label [red, handwritten]: "Pelidnota silveiranetoi sp. nov. / Ferreira / Vaz-de-Mello \& Bravo / HOLOTYPE". PARATYPE (o' CERPE): First label [white, typeset]: "BRAZIL: São Paulo, / Iracemápolis, / 11.ix.2011". Second label [yellow, handwritten]: "Pelidnota silveiranetoi sp. nov. / Ferreira / Vaz-de-Mello \& Bravo / PARATYPE". PARATYPE (ơ' ESALQ/USP): First label [white, typeset]: "BRAZIL: São Paulo, / Iracemápolis, / 11.ix.2011". Second label [yellow, handwritten]: "Pelidnota silveiranetoi sp. nov. / Ferreira / Vaz-de-Mello \& Bravo / PARATYPE".

Diagnosis: Body (dorsal and ventral) brown with metallic green reflections (Figs. 1A-C). Elytra brown, without metallic green reflections; black spots absent on the humerus and on the side of the elytra (Figs. 1A, C). Maxilla with galea bearing 3 teeth (Fig. 2C). Labium, anterior part with surface excavated; proximal margin straight; posterior part with lateral margin rounded (Fig. 2D). Parameres (in dorsal view) with distal margin concave, gradually acute and slightly divergent on the apex; lateral margin straight, and slightly sinuous at middle; proximal margin slightly corrugated (Figs. 5B, 6A).

Description (holotype, male): (Figs. 1A-C). Total length $24.07 \mathrm{~mm}$, width $11.7 \mathrm{~mm}$. Body elongated-oval (Figs. 1A-B), convex in lateral view (Fig. 1C). Color: Head, pronotum, scutellum, elytral suture and ventrally brown with metallic green reflections when exposed to fluorescent light; elytra brown without reflections, black spots absent on the humerus and on the side of elytra (Figs. 1A-B). Head: Antenna with antennal club elongated, longer than flagellomeres 1-5 combined. Clypeus trapezoidal in dorsal view, anterior margin straight, surface densely punctate. Fronto-clypeal suture not evident, pair of fronto-clypeal impressions present. Frons with surface moderately punctate; interocular distance $3.5 \times$ wider than eye diameter; inner margin of eyes with decumbent setae; ocular canthus length equal to half length of outer margin of eye (Fig. 3A). Labrum transversely elongated and not fused to clypeus, surface with medial concavity, with sparse setae (Fig. 2A). Mandibles not covered by anterior margin of clypeus, outer margin with 2 teeth, inner tooth $2 \times$ larger than external tooth, scissorial region with 2 teeth (Fig. 2B). Maxilla with galea bearing 3 teeth subequals; palpomere IV fusiform and elongated, shorter than palpomeres I-III combined (Fig. 2C). Labium, distal margin concave in medial portion; anterior part of disc with depressed concavity on surface; labial palp inserted on lateral surface, palpomere III fusiform and elongated, shorter than palpomeres I-II combined; posterior part of disc with elongated sparse setae on surface; proximal margin straight; lateral margin rounded with dense setae; surface with concavity longitudinal medially (Fig. 2D). Pronotum: Convex; total length $5.7 \mathrm{~mm}$, width at anterior angles $6.6 \mathrm{~mm}$, width at medial region $10.5 \mathrm{~mm}$, width at posterior angles $10.6 \mathrm{~mm}$; dorsal surface densely punctate, punctures small; proximal margin slightly convex in medial portion, sparse decumbent setae in lateral portion; sides regularly rounded, converging toward anterior angles; posterior margin convex in medial portion; posterior angles straight (Fig. 3A). Scutellum: Total length $1.4 \mathrm{~mm}$, width $2.2 \mathrm{~mm}$; surface moderately punctate without setae; anterior margin straight, posterior margin rounded. Elytra: Total length $15.9 \mathrm{~mm}$; width from base of elitral suture to humerus $5.8 \mathrm{~mm}$; surface without setae, sparsely punctate, punctures larger in size, irregularly organized in the first interval; elytral suture narrowing at apex; elytral apex conjointly truncated (Figs. 4A-B); pleural membrane expanded laterally from base to medial portion of elytra. Venter: surface with dense setae on mesoventrite and metaventrite, sparse setae on abdomen; surface moderately punctate on head and thorax, sparsely to moderately punctate on abdomen; prosternum elongated tubercle-shaped not extending beyond procoxa; mesoventrite with anterior process elongated, extending slightly beyond mesocoxa. Legs: surface moderately punctate on femur and tibia of all legs, with deep and irregular punctate on mesotibia and metatibia. Protibia with 3 external teeth, distal tooth positioned obliquely in relation to longitudinal axis of tibia, larger than medial tooth, proximal tooth $0.5 \times$ medial tooth; inner subapical spur present; dorsal surface irregularly punctate with a medial longitudinal carinae with sparse setae (Fig. 3B); tubercle present on apex of inner protarsal claw (Fig. 3C); metacoxa with posterior projection rounded and projecting beyond distal margin of metatrocanter. Metafemur with surface moderately punctate and sparse elongated setae; mesotibia with sparse elongated setae on inner surface and with sparse spine-like setae on outer surface; surface and insertion area of spine-like setae deeply sculptured. Metatibia enlarged continuously from medial to apical region; surface and insertion area of spine-like setae sculptured as in mesotibia; surface with two trans- 
versal carinae with 5 and 7 spine-like setae respectively; apical margin sinuous, with two spurs in different sizes (Fig. 5A). Tarsomere $\mathrm{V}$ elongated on all legs, with ventral margin laterally enlarged; protarsomere I elongated, as long as protarsomeres I-IV; mesotarsomeres and metatarsomeres II-IV with two spine-like setae on ventral surface.

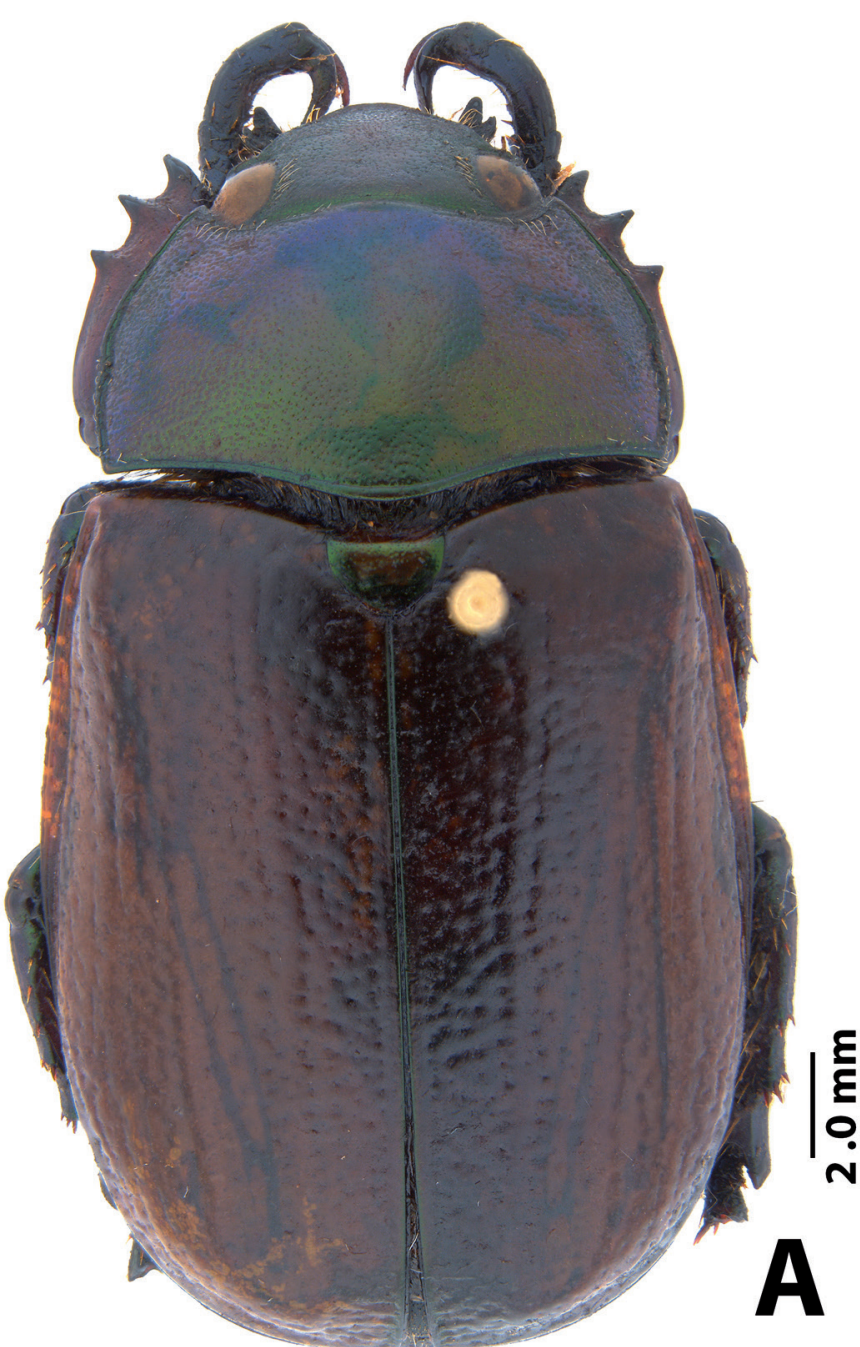

Abdomen: abdominal ventrites convex, sparse setae; surface sparsely to moderately punctate; ventrite $\mathrm{V}$ as long as ventrites III-IV; ventrite VI with concave distal margin. Pygidium: Slightly convex (Fig. 1C); with irregular transversal dense striae; sparse decumbent setae on base of disc. Parameres: Symmetrical, fused; length $0.5 \times$ base

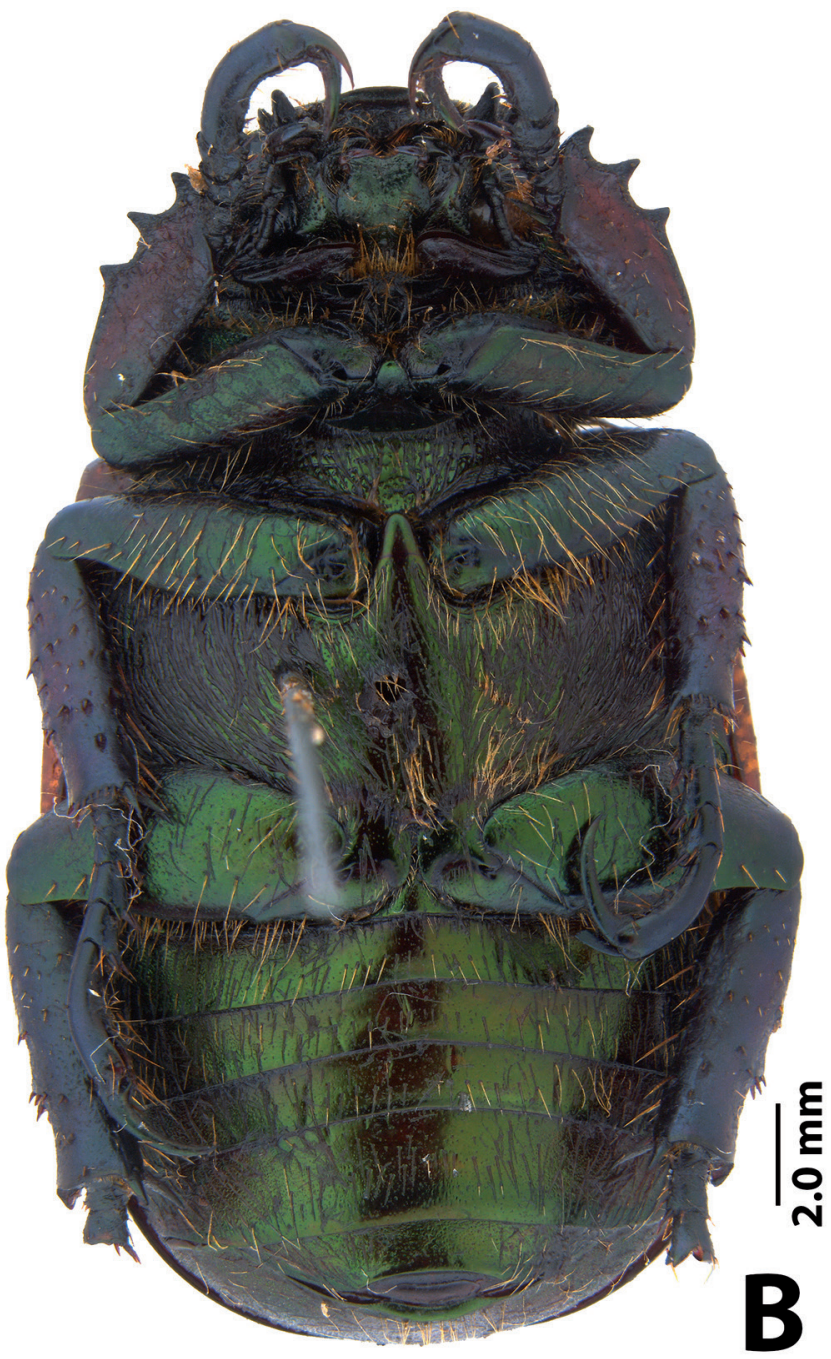

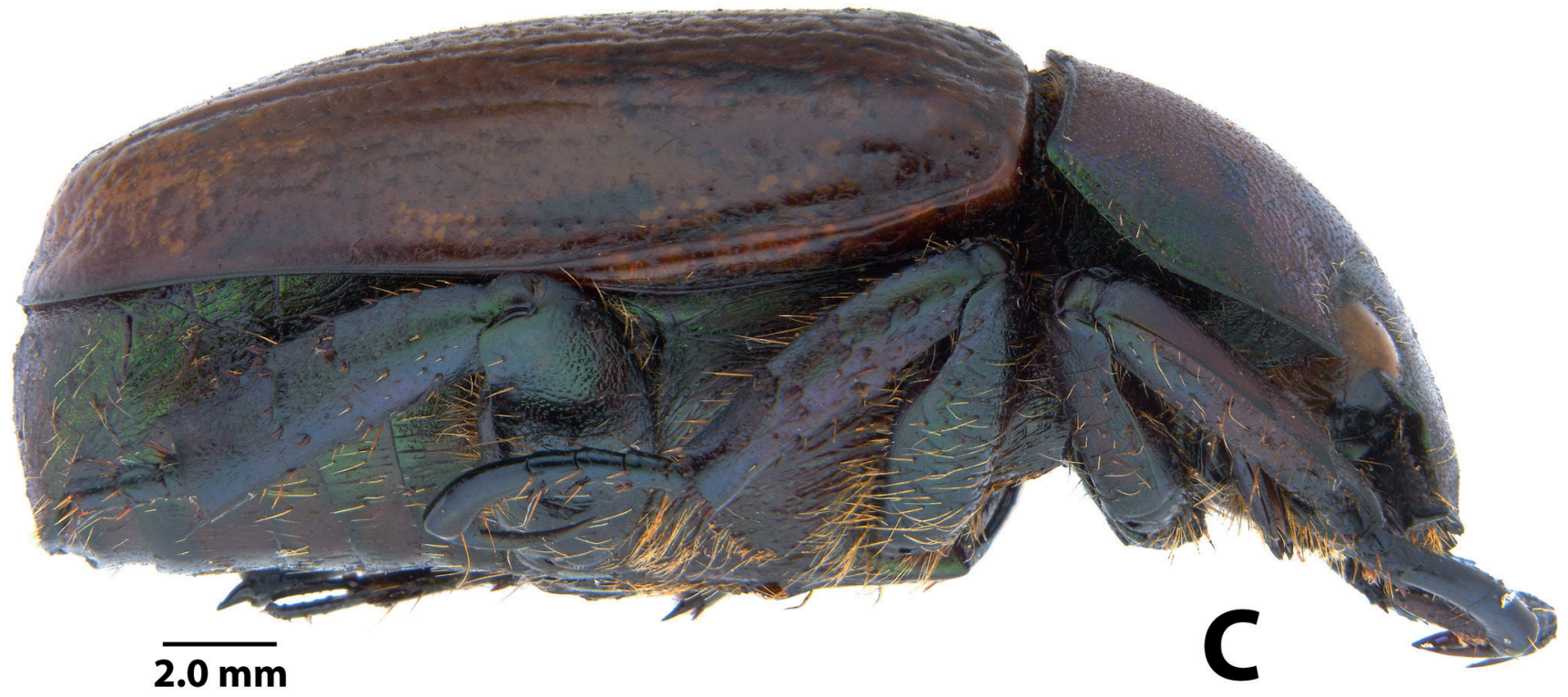

Figure 1. Pelidnota silveiranetoi sp. nov. Holotype, habitus: (A) dorsal; (B) ventral; (C) lateral. 
and phallobase combined; distal margin concave, gradually acute and slightly divergent on apex; lateral margin straight (dorsal view), lateral margin slightly sinuous at middle; proximal margin slightly corrugated (Figs. 5B-D).

\section{Female: Unknown.}

Morphological variation: The body length varies from $24.0 \mathrm{~mm}$ (Paratype) to $24.07 \mathrm{~mm}$ (Holotype). Clypeus of the paratypes with the surface slightly more densely punctate, lateral and anterior margins slightly straighter than in the Holotype.

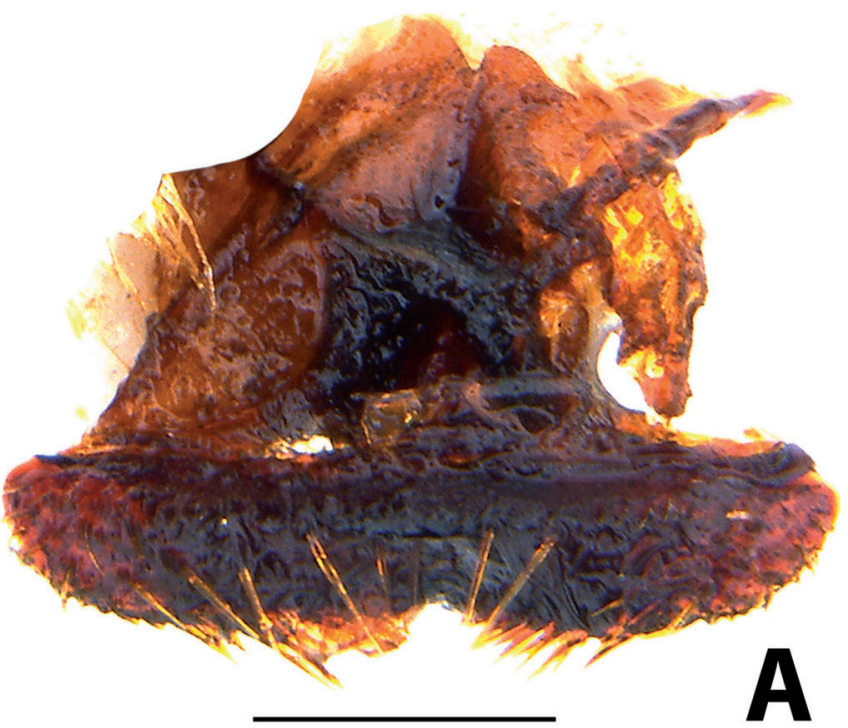

\section{$1.0 \mathrm{~mm}$}

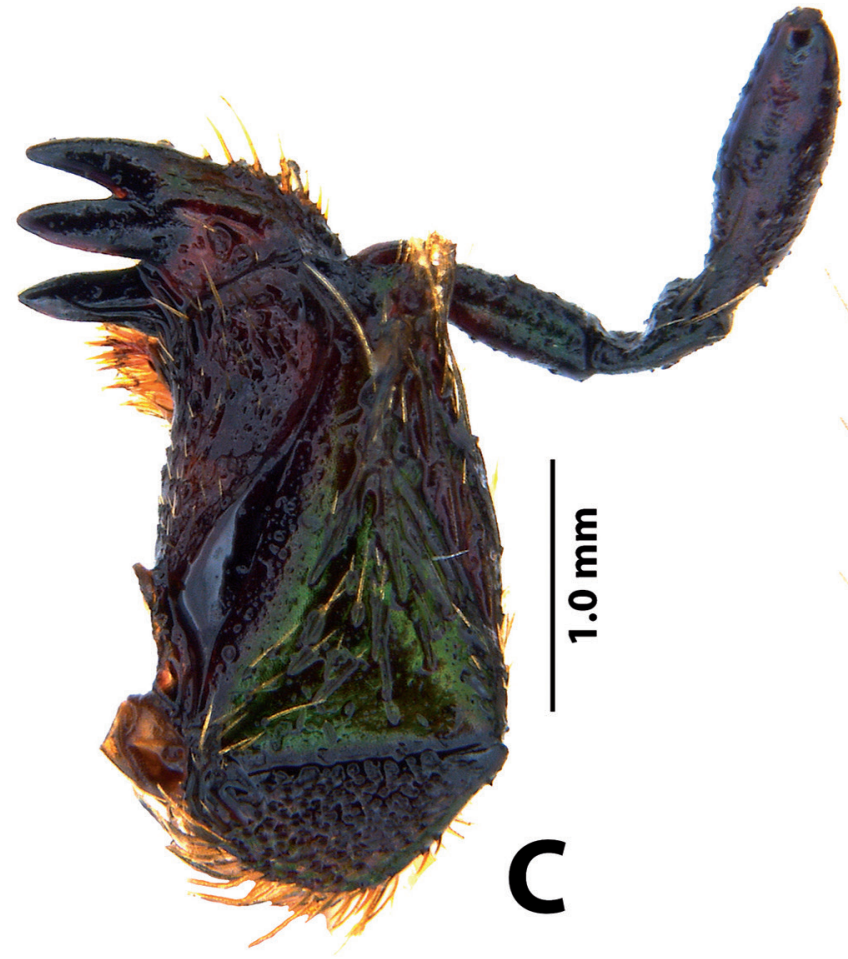

Etymology: This species is named in honor of Dr. Sinval Silveira-Neto (Museu de Entomologia, Departamento de Entomologia, Fitopatologia e Zoologia Agrícola, Campus Luiz de Queiroz - ESALQ/Universidade de São Paulo), who provided the specimens for study.

Distribution: The new species is known only from the type locality (Iracemápolis, São Paulo state) (Fig. 7).

Remarks: Pelidnota silveiranetoi sp. nov. is morphologically similar to Pelidnota chalcothorax Perty, 1830, mainly considering the color of the elytra. However, in
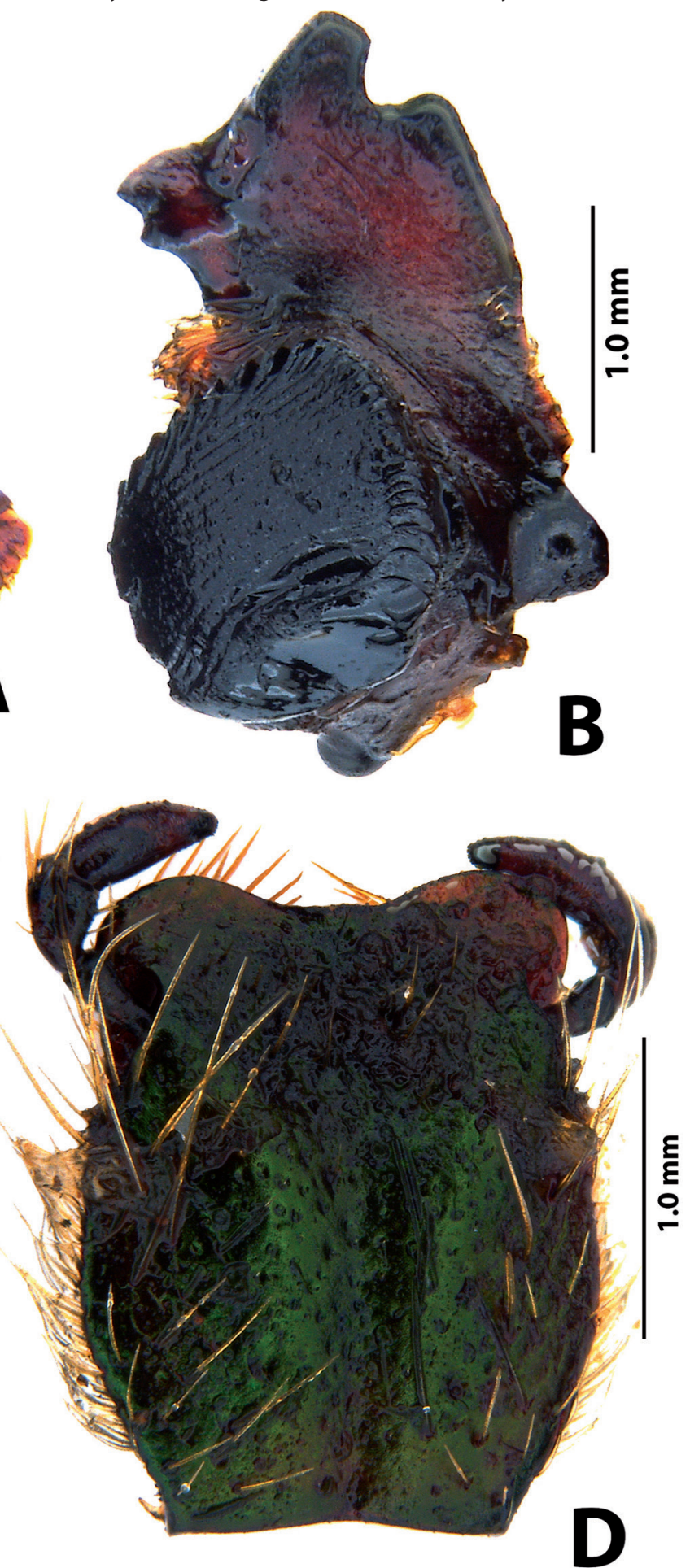

Figure 2. Pelidnota silveiranetoi sp. nov. Paratype: mouthparts: (A) labrum, dorsal; (B) left mandible, dorsal; (C) left maxilla, ventral; (D) labium, ventral. 

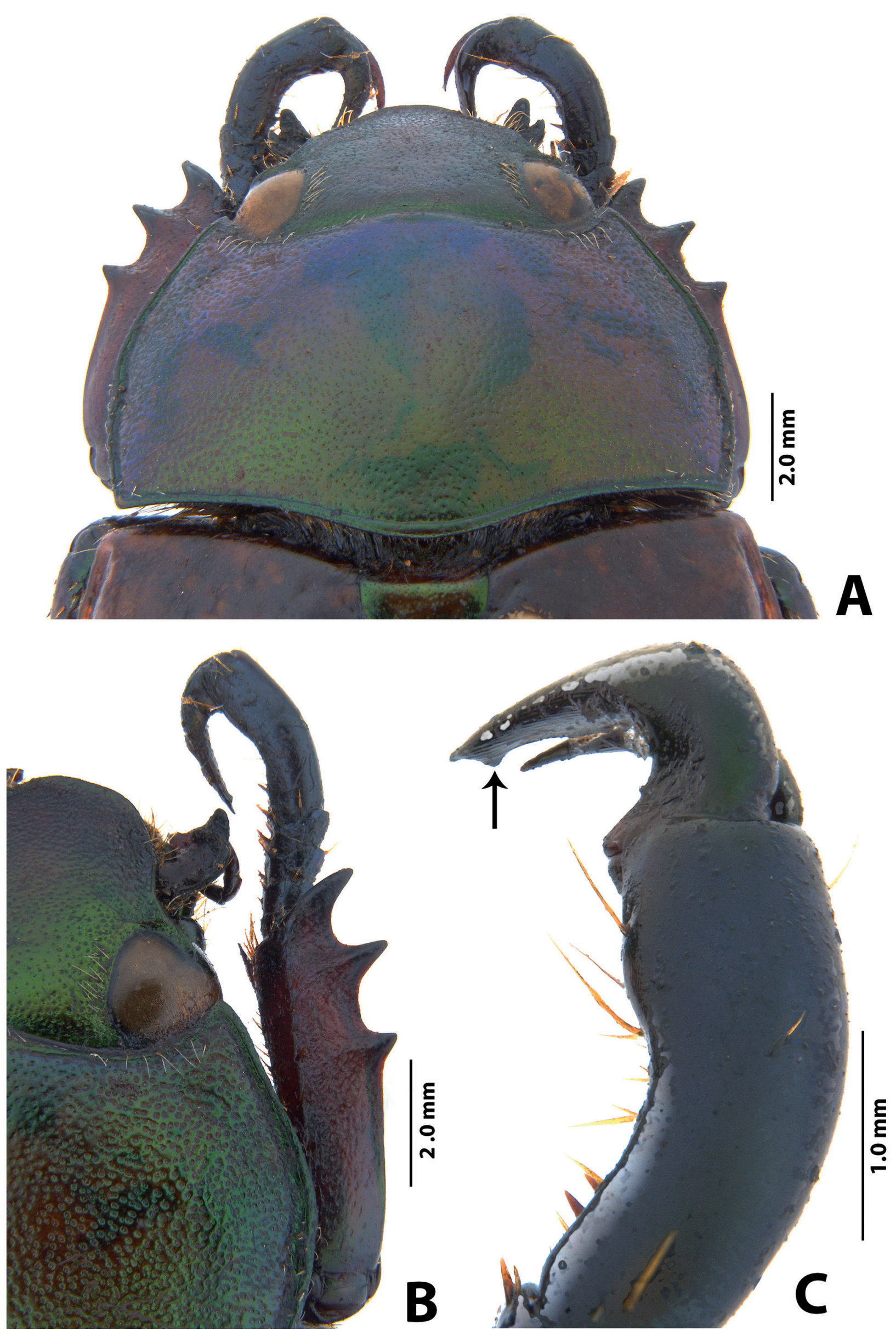

Figure 3. Pelidnota silveiranetoi sp. nov. Holotype: (A) head and pronotum, dorsal; (B) right protibia, dorsal; (C) protarsomere V, dorsolateral view. Black arrow shows the tubercle on the apex of the inner protarsal claw. 
Pelidnota silveiranetoi sp. nov., the body (dorsal and ventral) is brown with metallic green reflections; elytra with metallic green reflections only on the elytral suture; and black spots absent on the humerus and the side of the elytra. On the other hand, P. chalcothorax has a dark brown body (dorsal and ventral) with the head, pronotum, scutellum, pygidium, and legs darker than the elytra, without metallic green reflections; elytra with
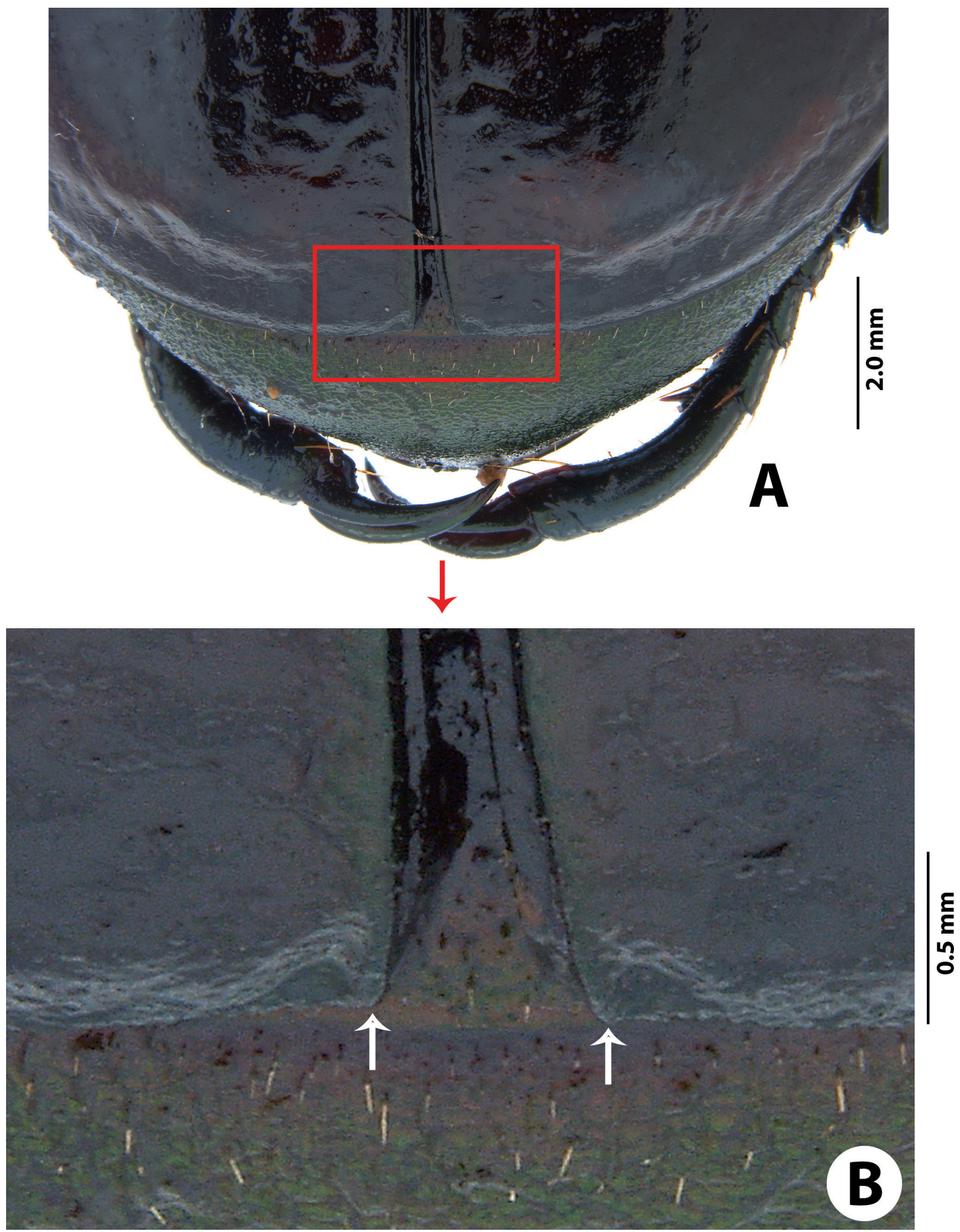

Figure 4. Pelidnota silveiranetoi sp. nov., elytral apex: (A) dorsal; (B) detail. White arrows show the elytral apex. 
green reflections completely absent, but with black spots on the humerus and side of the elytra. Moreover, in Pelidnota silveiranetoi sp. nov., the parameres have concave distal margins gradually acute and slightly divergent on the apex; straight lateral margins slight- ly sinuous at the middle; slightly corrugated proximal margins (Fig. 6A). In P. chalcothorax, the parameres have slightly concave distal margins, rounded lateral apex; semi-straight lateral margins; convex proximal margin (Fig. 6B).
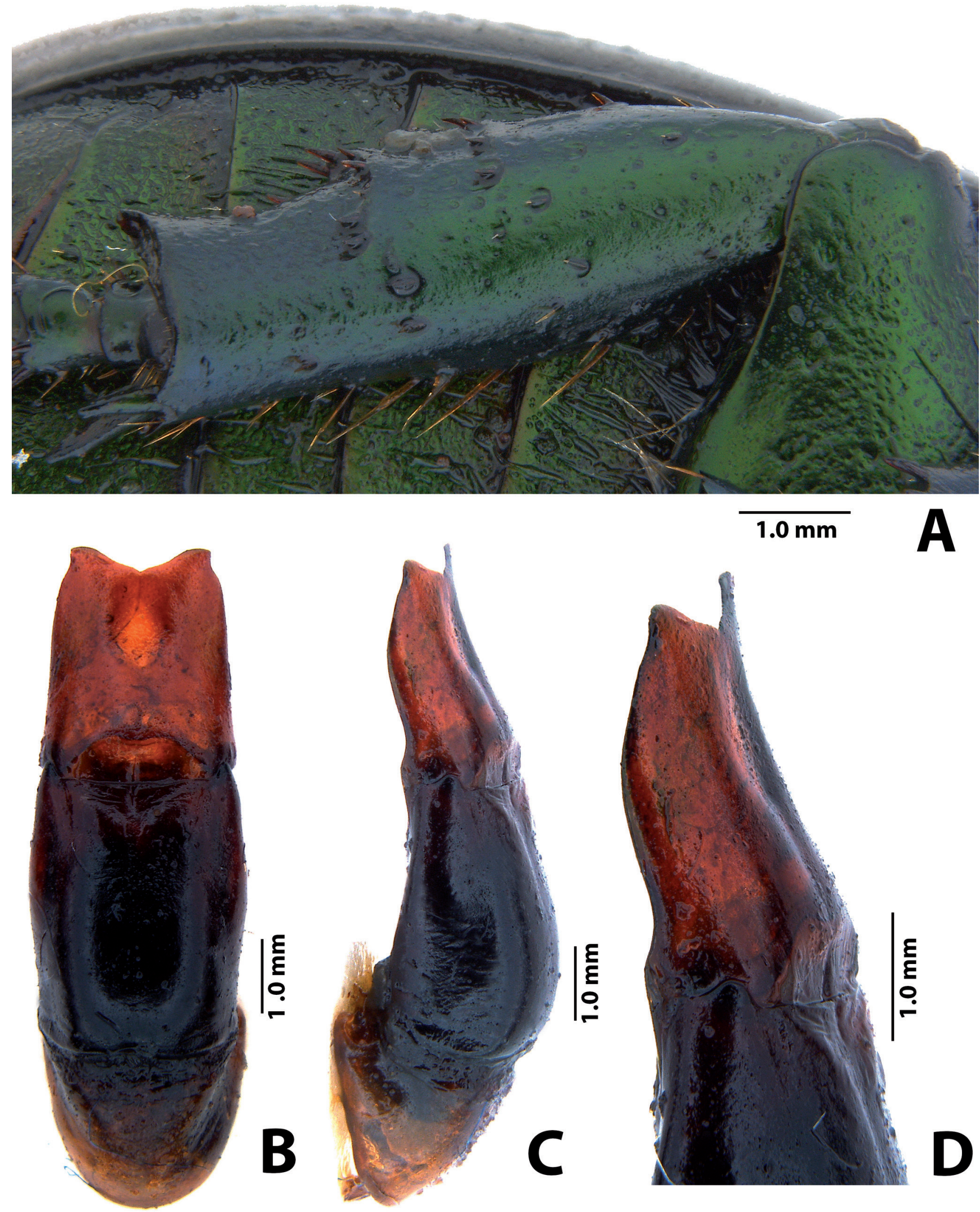

$1.0 \mathrm{~mm}$

Figure 5. Pelidnota silveiranetoi sp. nov. Holotype: (A) Metatibia, ventral; (B-D) male genitalia, aedeagus: dorsal (B), lateral (C-D). 


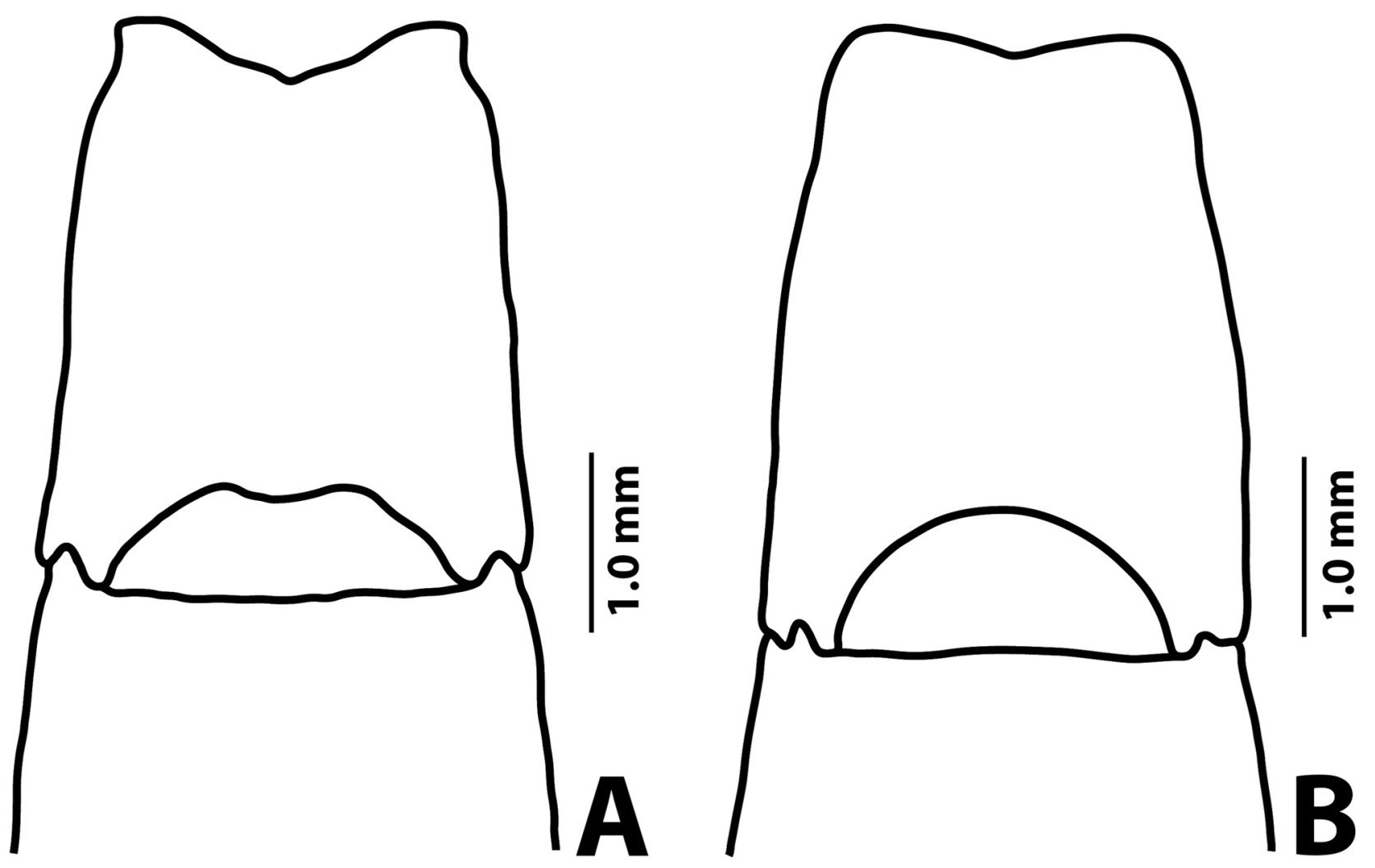

Figure 6. Parameres (dorsal): (A) Pelidnota silveiranetoi sp. nov., (B) Pelidnota chalcothorax Perty.

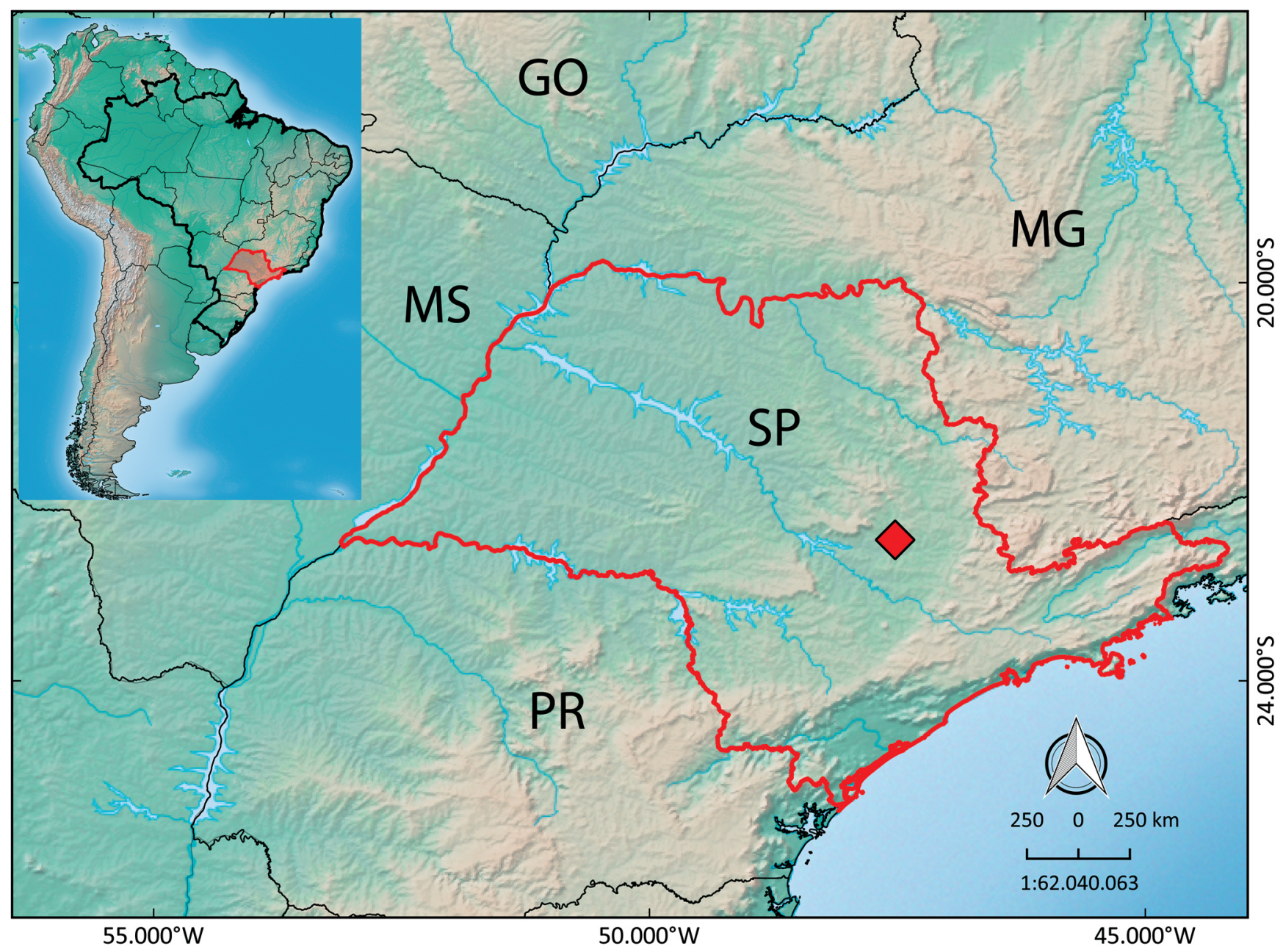

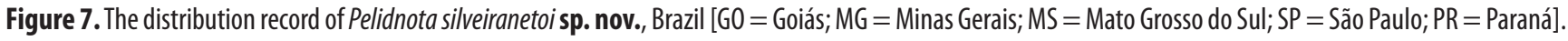


The geographic distribution of Pelidnota silveiranetoi sp. nov. has so far been restricted to the aforementioned type locality, while $P$. calchothorax has been recorded in Brazil with type locality São Paulo (Perty, 1830: 48) and Bahia, Espírito Santo, Minas Gerais, Rio de Janeiro, São Paulo, and Mato Grosso (Soula, 2009; Moore et al., 2017; Ferreira et al., 2018).

\section{Identification key}

Pelidnota silveiranetoi sp. nov. was included in couplet 48(43) of the identification key for the species Pelidnota (Soula, 2009: 30-34, modified by Ferreira et al., 2017: 221).

48(43). Uniformly brown dorsal surface ....A

- Dark brown body with or without green reflections .............................

$A(48)$. Black spots present on the elytra or pronotum; brown body, with legs and ventral surface darker than the dorsal surface................... B Black spots absent on the elytra and pronotum (Figs. 9-10, see Ferreira et al. (2017): 210); brown body with legs darker than the dorsal surface. Distribution: BRAZIL (Pernambuco, Bahia, Espírito Santo, Minas Gerais, Rio de Janeiro, São Paulo, Santa Catarina), PERU (see Moore et al. (2017); Ferreira et al. (2018)) Pelidnota unicolor unicolor (Drury)

$A^{\prime}(48)$. Body without metallic green reflections; elytra with lateral black spots. Parameres with slightly concave distal margin, rounded lateral apex; semi-straight lateral margin; convex proximal margin (Fig. 6B). Distribution: BRAZIL: Atlantic Forest and deciduous forest (Caatinga), states of Bahia, Espírito Santo, Minas Gerais, Rio de Janeiro, São Paulo, Mato Grosso (see Ferreira et al., 2017; Moore et al., 2017; Ferreira et al., 2018)........... Pelidnota chalcothorax Perty Body with metallic green reflections, except on the elytra; lateral black spots absent from the elytra. Parameres with concave distal margin gradually acute and slightly divergent on the apex; straight lateral margin slightly sinuous at the middle; slightly corrugated proximal margin (Fig. 6A). Distribution: Brazilian Atlantic Forest, São Paulo state Pelidnota silveiranetoi sp. nov. (Figs. 1A-C)

\section{ACKNOWLEDGMENTS}

The first author is grateful to Coordenação de Aperfeiçoamento de Pessoal de Nível Superior (CAPES) for the PhD fellowship - Finance Code 001 (Process number: 1629785 and 88882.453921/2019-01); FZVM is a $1 \mathrm{~B} \mathrm{CNPq}$ fellow and is funded by CNPq and FAPEMAT; Freddy Bravo received a research grant from Conselho Nacional de Desenvolvimento Científico e Tecnológico (CNPq) (Process number: 305855/2019-0). The authors also thank the anonymous reviewers for improving the critical revision process.

\section{AUTHORS' CONTRIBUTIONS}

A.S.F.: Species identification and capturing and preparation of the images, Writing - original draft. F.Z.V.M. and F.B.: Writing - review \& editing. All authors have read and approved the final version of the manuscript.

\section{REFERENCES}

Beutel, R.G. \& Lawrence, J.F. 2005. 4. Coleoptera, morphology. In: Beutel, R.G. \& Leschen, R.A.B. (Eds.). Handbuch der Zoologie/Handbook of Zoology, Band/Volume IV, Arthropoda: Insecta Teilband/Part 38, Coleoptera, Beetles, Volume 1:Morphology and Systematics (Archostemata, Adephaga, Myxophaga, Polyphaga partim). Berlin, W. de Gruyter. p. 23-27. D0I

Bouchard, P.; Bousquet, Y.; Davies, A.E.; Alonso-Zarazaga, M.A.; Lawrence, J.F.; Lyal, C.H.C.; Newton, A.F.; Reid, C.A.M.; Schmitt, M.; Ślipiński, S.A. \& Smith, A.B.T. 2011. Family-group names in Coleoptera (Insecta). ZooKeys, 88: 1-972. D0I

Ferreira, A.S.; Almeida, L.M. \& Bravo, F. 2017. Three new species of Pelidnota MacLeay (Coleoptera, Scarabaeidae, Rutelinae) and new distributional records from northeast Brazil. Revista Brasileira de Entomologia, 61(3): 208-223. DOI

Ferreira, A.S.; Almeida, L.M.; Bravo, F. \& Grossi, P.C. 2018. A checklist of Rutelinae MacLeay, 1819 (Coleoptera, Melolonthidae) of Bahia, Brazil. Biota Neotropica, 18(2): e20170476. DOI

Grossi, P.C. \& Vaz-de-Mello, F.Z. 2020. Melolonthidae in Catálogo Taxonômico da Fauna do Brasil. PNUD. Available: http://fauna.jbri.gov.br/fauna/ faunadobrasil/127378. Access: 24/11/2020.

Jameson, M.L. \& Ratcliffe, B.C. 2011. The Neotropical scarab beetle tribe Anatistini (Coleoptera: Scarabaeidae: Rutelinae). Bulletin of the University of Nebraska State Museum, 26: 1-100.

Lawrence, J.F.; Beutel, R.G. \& Leschen, R.A.B. 2010.2 Glossary of morphological terms. In: Leschen, R.A.B.; Beutel, R.G. \& Lawrence, J.F. (Eds.). Handbuch der Zoologie/Handbook of Zoology, Band/Volume IV, Arthropoda: Insecta Teilband/Part 38, Coleoptera, Beetles. Vol. 2. Morphology and Systematics (Polyphaga partim). Berlin, Walter de Gruyter, p. 9-20. DOI

Moore, M.R.; Jameson, M.L.; Garner, B.H.; Audibert, C.; Smith, A.B.T. \& Seidel, M. 2017. Synopsis of the pelidnotine scarabs (Coleoptera, Scarabaeidae, Rutelinae, Rutelini) and annotated catalog of the species and subspecies. Zookeys, 666: 1-349. D0I

Perty, J.A.M. 1830. Insecta Brasiliensia, In: Perty, J.A.M. (1830-1833). Delectus animalium articulatorum, quae in itinere per Brasiliam annis MDCCCXVII-MDCCCXX jussu et auspiciis Maximiliani Josephi I. Bavariae regis augustissimi peracto collegerunt Dr. J.B. de Spix et Dr. C.F. Ph. de Martius. Munich, Impensis Editoris. p. 1-60.

Soula, M. 2009. Les Coléoptères du Nouveau Monde. Volume 3: Rutelini 3. Révision des Pelidnotina 3. Photos de toutes les espèces de Lagochile. Une révision des genres Pelidnota, Ectinoplectron, Pseudogeniates, Xenopelidnota (Coleoptera: Scarabaeidae: Rutelinae: Rutelini: "Pelidnotina"). Besoiro. Saintry, I'Association Entomologique pour la Connaissance de la Faune Tropicale. AECFT. p. 25-116. (Supplément au Bulletin de liaison AECFT) 